\section{Possibilidades de Redução das Desigualdades Educacionais em Estados Federais e Unitários: Brasil e Chile.}

Possibilities for Reducing Educational Inequalities in Federal and Unitarian Countries: Brazil and Chile.

Emílio Araújo'

\section{Resumo:}

Este artigo é uma abordagem de pesquisa que investiga as possibilidades que Estados Federais e Unitários possuem para, a partir das políticas de financiamento educacional reduzir as desigualdades educacionais entre suas regiões. A partir da constatação de que as desigualdades gritantes que marcam negativamente a América Latina, com graves consequêencias nos resultados educacionais da maioria das populações nacionais, tem intenção de responder as seguintes perguntas: 1. os mecanismos de financiamento educacional são capazes de reduzir as diferenças de capacidade de gasto por aluno entre as diferentes regiões dos países estudados?; 2. a partir da ação dos governos nacionais se efetiva uma redução da capacidade de financiamento

Palavras-chave: Desigualdades educacionais; Estados Unitários; Estados Federais; Políticas educacionais; Financiamento da educação. das matrículas e/ou uma descriminação positiva que induza melhorias educacionais nas regiões mais pobres?; 3. a forma de governo federal ou unitária é determinante nesses processos? Este trabalho sobre o Brasil e Estados Unitários, como o Chile, revela que a resposta a essas perguntas depende da organização dos sistemas educativos nacionais e o pape que cabe nela aos governos nacionais, da arrecadação e divisão tributária nacional entre os níveis de governo nacional e subnacionais Esses fatores que, em Estados Unitários, como o Chile, tendem a concentrar-se mais no Governo Nacional, permitem uma ação mais efetiva, com mais recursos para as regiões mais pobres, criando condições para diminuir as desigualdades nos resultados educacionais.
Abstract:

This article is an approach of a research that searches possibilities that Federal and Unitarians States have to reduce educational inequalities among their regions considering the politics of educational funds. From the observation that the strong inequalities that mark Latin America negatively, with serious consequences in the educational outcomes of most national populations, this search intends to answer the following questions: 1 . Can the mechanisms of educational funds reduce the differences expenses per student among different regions of the searched countries? 2. Is there a decrease of the registration's financing or a reduction of positive discrimination, from the action of national governments that induces to educational improvements in the poorest regions? 3. No matter being Federal or Unitarian, are government's forms decisive in these processes? This work about Brazil and Unitarian States, like Chile, shows that the answer to these questions depends on the organization of the educational systems of each country and also depends upon the national and the sub national governments, the national tax collection and the tributary division These factors, that in Unitarians states such as Chile, inclines to concentrate on the National Government, permit an effective action to have more recourses to help the poorest regions and, in this way, creating conditions to reduce inequalities in educational results. 


\section{1. $O$ cenário}

A fantástica ampliação dos sistemas educacionais latino-americanos, na segunda metade do século $X X$, não foi suficiente para democratizar a educação. Enquanto a população de 5 a 24 anos dos países latinos cresceu, entre 1950 e 1980, de 67 para 156 milhões, pouco mais de 2,3 vezes, a população escolarizada da mesma faixa de idade cresceu quase nove vezes, aumentando de 11 para 87 milhões. A taxa de atendimento escolar, de $17 \%$ em 1950 alcançou 56\% em 1980 (RAMA, 1983, p. 17).

O Brasil, segundo dados do IBGE, apresentava em 1950, taxa de atendimento escolar da população de 5 a 19 anos de idade de $26,15 \%$, em 2000 , atendia a $94,73 \%$ da população de 7 a 14 anos de idade. Ainda assim classifica-se entre os países com os piores indicadores de desempenho educacional. A tabela 1 mostra que os índices dramáticos de analfabetismo, principalmente nas regiões mais pobres do país.

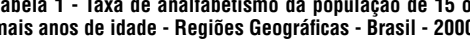

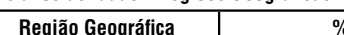

\begin{tabular}{|c|c|}
\hline Região Geográfica & $\%$ \\
\hline Norte & 16,3 \\
\hline Nordeste & 26,2 \\
\hline Sudeste & 8,1 \\
\hline Sul & 7,7 \\
\hline Centro-Oeste & 10,8 \\
\hline Fonte: IBGE
\end{tabular}

\section{IBGE}

Juan Carlos Tedesco (II CONGRESSO NACIONAL E I ENCONTRO LATINOAMERICANO DE ESTUDOS COMPARADOS EN EDUCACIÓN, 2007), para sustentar sua opinião de que a realidade continua muito ruim, exemplifica que, no Chile dos 15 anos anteriores, apesar de todos os indicadores educacionais terem melhorado, ainda assim os resultados escolares melhoraram pouco. Mais grave: mantiveram-se "as diferenças, a desigualdade e os resultados de aprendizagem dos alunos que vêm de famílias de classe média alta e os que vêm das famílias de setores populares"

Constatações dessa importância denunciam que a tentativa de generalizar um pacote de mudanças educacionais no continente, nas últimas décadas, não foi suficiente para responder aos grandes dilemas dos sistemas nacionais de educação. $O$ que também pode ser visto nas lutas sociais e/ou nos esforços de governos de países que, durante os anos 1980 e 1990, foram utilizados como exemplos de políticas educacionais para o resto do continente. No Chile, as mobilizações dos estudantes do Ensino Médio - apelidada de Revolta dos Pingüins - pretende, dentre outras reivindicações, a revogação da Lei Orgânica de Ensino, originária da ditadura de Pinochet e ainda em vigor nos governos democráticos. $\mathrm{Na}$ Argentina, o Governo Nestor Kirchner mudou a legislação de financiamento educacional aprovou nova Lei da Educação Nacional.

sso mostra a atualidade das reflexões sobre os caminhos não apenas para melhorar o desempenho dos sistemas educacionais, mas principalmente para reduzir as incriveis desigualdades que se manifestam na escolarização das populações nacionais.

Este trabalho é uma primeira aproximação de uma pesquisa, na qual são analisadas as possibilidades que os Estados federais e unitários possuem para atuar, a partir das políticas de financiamento, na redução das desigualdades educacionais entre as diferentes regiões.

Daí a importância de analisar as estruturas políticas dos países, considerando inicialmente, três aspectos fundamentais: a forma de governo, se unitária ou federal; a responsabilidade pela oferta educacional, se centralizada no governo nacional ou transferida aos governos subnacionais, além das responsabilidades que cabem ao governo central e; a estrutura de financiamento educacional, essencialmente aquela que propicia condições para reduzir as desigualdades na capacidade de financiamento das matrículas entre as diferentes regiões.

Nos Estados Unitários os governos locais dispõem de menos autonomia do que nos Estados Federativos, pois
Apenas o governo central tem autoridade política própria derivada do voto popular direto A unidade do Estado Nacional está garantida pela concentração de autoridade política, fiscal e militar no governo central, ao passo que a autoridade política dos governos locais é derivada de uma delegação de autoridade autoridade política central (ARRETCHE, 2002, p. 28).

São cada vez mais freqüentes, como diz Abrucio (2003, p. 230-231) os esforços de países unitários para "flexibilizar as formas de relacionamento do governo central com os outros entes", mas não podemos desconsiderar que tal "distribuição de poder obedece a uma hierarquia e a uma assimetria entre o poder nacional e a unidades subnacionais". As decisões sobre "desconcentração de poder" são submetidas à aprovação de "instâncias do nível central" que não contam com representantes vinculados à defesa dos direitos de uma determinad região. Portanto, "governos ou administrações subnacionais não possuem direitos originários" e "soberania nacional é fruto de um contrato entre todos os indivíduos da nação".

Os Estados Federativos, ao contrário, guardam como uma de suas mais importantes características a independência entre o governo central e os governos locais. Nesse sentido, a unidade nacional resulta

de um pacto entre as unidades territoriais que escolheram estabelecer uma parceria, conformando uma nação [...] [uma] união voluntária entre os cidadãos dos territórios constituintes, que mantêm seus direitos originários, mas cujo produto é a constituição de um governo nacional autônomo, ao contrário do que ocorre nas Confederações (lbidem, p. 232).

Nas últimas décadas, as pressões pela descentralização de diferentes ações dos Estados nacionais se desenrolaram nos quatro cantos do Mundo, com motivações em contextos significativamente diferentes. Elemento essencial das políticas de ajuste liberal dirigidas pelos organismos financeiros internacionais, constituíram-se também numa atitude reativa por parte de importantes setores sociais de diferentes países, especialmente depois de experiências com regimes autoritários com características centralizadoras, como no caso do Brasi (ARRETCHE, 2002).

Espinoza \& Gonzáles (1993, p. 13-15) evidenciam a complexidade da temática da descentralização ao relacionarem "elementos" das políticas educacionais que podem ser descentralizados: a provisão dos recursos para o financiamento educacional que podem até mesmo, ser cobrados das famílias; a destinação dos recursos, que pode ser feita aos governos subnacionais, às escolas ou às famílias; a administração dos estabelecimentos e dos bens móveis e equipamentos escolares, que podem continuar como propriedade dos governos subnacionais ou mesmo da comunidade escolar; a administração dos recursos financeiros e materiais pelos governos subnacionais ou pelas próprias escolas; etc.

Para efeito deste trabalho, a descentralização está relacionada às responsabilidades pelo atendimento e pelo financiamento educaciona assumidas pelos governos locais a partir de rransferências dos governos nacionais, ou resultante dos processos de constituição dos sistemas educativos nacionais.

\section{Chile: uma nação de enigmas}

Desde a República, o Chile declarou-se um Estado Unitário, o que foi determinante no caráter centralizado tanto da administração pública, como da organização e administração educacional. O Governo Central tinha a principal responsabilidade pela oferta de educação, o que levou à denominação de Estado docente (LEAL e CASTRO, 1991).

Desde 2007, foi estabelecida nova divisão territorial do país, que passou a ter 15 regiões, 53 províncias e 346 comunas. Tanto os Intendentes Regionais, como os Governadores das Províncias e os prefeitos das municipalidades eram designados pelo Presidente da República. A partir de 1988, os prefeitos passaram a ser eleitos pelos Conselhos Regionais de Desenvolvimento (COREDE) e, de 1992 em diante, são eleitos pelo voto popular. 
O golpe militar que, em 1973, colocou fim oo governo da Unidade Popular, liderado por Salvador Allende, instalou uma ditadura, a qual tem muitos motivos para ser caracterizada como a mais sanguinária dentre as que se instalaram na América Latina entre os anos 1960 e 1970. Também é o período em que se realizam os primeiros experimentos de ajuste neoliberal, dando forma às orientações dos economistas da Universidade de Chicago, que desde o final dos anos 1950 desenvolviam acordos de cooperação com a Universidade Católica do Chile, que viria a emprestar os quadros dirigentes do governo Pinochet (MORAES, 2001)

O centralismo e a suposta ineficiência do sistema educacional eram os aspectos principais do diagnóstico da Junta Militar, presente no documento "Bases para a Política Econômica del Gobierno Militar". A Declaração de Princípios da Honorável Junta de Governo de 1974, é coerente com esse diagnóstico, ao estabelecer que o Estado deveria restringirse à propriedade apenas daquilo que não pudesse ser transferido para as mãos de particulares, comprometendo-se a fundar uma sociedade apoiada na descentralização e no conceito de Estado Subsidiário (ESPINOZA e GONZÁLEZ, 1993)

\section{0 Sistema de ensino e o}

\section{financiamento educaciona}

O sistema educacional chileno está organizado em três níveis de ensino. A Educação Infantil ou Parvulária compreende seis anos de escolaridade, divididos no primeiro ciclo, entre 0 e 2 anos de idade, segundo ciclo, entre 3 e 5 anos de idade. A Educação Básica é dividida em primeiro ciclo básico, a partir de seis anos, com quatro anos de duração, e segundo ciclo básico, também com quatro anos de duração. O Nível Médio, que desde maio de 2003, compreende junto com a Educação Básica, a escolarização obrigatória, pode ser cursado em duas modalidades, ambas com quatro anos de duração: científico humanista, apenas com estudos gerais, ou técnico profissional, com dois anos de estudos gerais seguidos de dois anos de formação profissional.

Em 2002, cerca de $63 \%$ das escolas e $33 \%$ dos alunos tinham sido incorporados à Jornada Escolar Completa - JEC -, uma das principais inovações dos governos do período democrático, que elevou a carga horária semanal dos alunos da Educação Básica a 38 "horas pedagógicas de 45 minutos", totalizando 1.467 horas anuais $e$ para os alunos do Ensino Médio, 42 horas, que totalizam 1.621 horas anuais.

Além das subvenções transferidas pelo Estado, as mantenedoras municipais dispõem de três outras fontes de financiamento para suas escolas: 1 . investimentos do Ministério do Interior através do Fundo Nacional de Desenvolvimento Regional (FNDR), aos quais as escolas concorrem através da apresentação de projetos; 2. recursos das receitas das municipalidades que são transferidos às mantenedoras municipais; 3. recursos da Lei de Doações com Fins Educacionais, que representam, no entanto, uma quantidade limitada de recursos, que dependem da elaboração de um projeto pela escola e pela empresa doadora.

Desde o início dos anos 1980 é praticado um amplo e generalizado sistema de subvenção às matrículas que se estende tanto às escolas transferidas às municipalidades como às escolas particulares que aderem ao sistema de subvenções pago pelo Governo Nacional, através do Ministério da Educação (MINEDUC). Existem diversos tipos de subvenção correspondentes a cada modalidade e nível de ensino, variando ainda de acordo com a localização geográfica, as características da população atendida e as dificuldades e especificidades próprias do ensino - como mostra, resumidamente, a tabela 2
Tabela 2 - Subvenção por aluno por nível e modalidade Chile - Ano 2000 - em pesos

\begin{tabular}{|c|c|c|}
\hline & Com JEC diurna & Sem JEC diurna \\
\hline $\begin{array}{l}\text { Parvulária }\left(2^{\circ} \text { nivel }\right. \\
\text { de transición }\end{array}$ & & $16.815,08$ \\
\hline $\begin{array}{c}\text { Educação G Básica } \\
\left(1^{\circ} \mathrm{a} 8^{\circ}\right)\end{array}$ & $23.085,85$ & $18.292,78$ \\
\hline Ensino Médio CH & $27.595,45$ & $20.426,87$ \\
\hline $\begin{array}{l}\text { Ensino Médio TP } \\
\text { Agrícola }\end{array}$ & $37.383,15$ & $30.279,22$ \\
\hline $\begin{array}{c}\begin{array}{c}\text { Ensino Médio TP } \\
\text { Industrial }\end{array} \\
\text { In }\end{array}$ & $29.157,23$ & $23.618,30$ \\
\hline $\begin{array}{l}\text { Educacãão Básica de } \\
\text { Adultos }\end{array}$ & & 198,41 \\
\hline
\end{tabular}

Fonte: MINEDUC. Com

Durante os governos da democracia foram aperfeiçoadas as regras para o financiamento compartilhado, onde as escolassubvencionadas podem cobrar mensalidade das famílias, o que acarreta uma progressiva redução dos valores pagos como subvenção. Além das escolas particulares subvencionadas, entre as quais 93\% praticavam este sistema em 2000, apenas as de Ensino Médio das municipalidades podem pedir a aprovação dos pais para a cobrança, 0 que pode justificar que, em 2000 , apenas $7 \%$ estavam incluídas no sistema.

O Estado assegura às escolas apoio técnico e insumos materiais - textos de estudo gratuitos, bibliotecas para todos os alunos da Educação Básica, benefícios assistenciais aos estudantes de "poucos recursos", aperfeiçoamento gratuito dos docentes, programas de melhoramento da qualidade educativa e assessoria técnica.

\section{A descentralização e o financiamento educacional pelos diferentes níveis de governo}

$O$ atendimento educacional do país passou por radicais transformaç̃̃es a partir dos anos 1980. Num sentido, as escolas do MINEDUC foram transferidas para as municipalidades, o que fo facilitado por umanova Lei Orgânica dos Municípios e da Administração Municipal, que subordinou os prefeitos aos Governadores das Províncias aos Intendentes Regionais e definindo-os como executores das políticas determinadas pelos níveis superiores de governo, além da liberalização do mercado de trabalho dos professores, que perderam a condição de servidores públicos, passando a ser regidos pelo Código do Trabalho, comum a todos os trabalhadores chilenos, com seus salários fixados pelas municipalidades ou pelas mantenedoras privadas.

Noutro sentido, a ditadura militar garantiu um conjunto de incentivos que, num curto período de tempo, beneficiaram a ampliação das matrículas das escolas particulares subvencionadas: facilitou créditos para construção ou o equipamento de escolas subvencionadas, fixou uma subvenção mínima para as escolas com um número insuficiente de alunos, passou a pagar às escolas particulares valores iguais aos pagos às escolas públicas criou um sistema de correção automática do valor pago às escolas e autorizou uma quantidade maior de alunos por turma (ESPINOZA e GONZÁLEZ, 1993)

$O$ processo de municipalização das escolas se deu num tempo muito curto. Em 31 de dezembro de 1980, foram transferidas às municipalidades 362 escolas com 67.208 alunos, em 19 comunas do país. Até abril de 1982, haviam sido transferidas 5.724 escolas do MINEDUC para as comunas, num total de dois milhões de alunos. A transferência das últimas 23 escolas foi realizada em agosto de 1986 (Ibidem, p. 123-139).

A tabela 3 mostra o movimento das matrículas do MINEDUC (fiscais) na direção das municipalidades, das particulares subvencionadase, atémesmo, das particulare pagas. Em 2000, as municipalidades, que não tinham nenhuma matrícula em 1981, eram responsáveis por mais de $53 \%$ do atendimento educacional dos níveis de ensino anteriores ao Ensino Superior. A municipalização das escolas, não só não impediu como facilitou a redução do atendimento público de quase $78 \%$ para menos de $54 \%$. Esse movimento foi devidamente acompanhado po impressionante crescimento das matriculas particulares subvencionadas, que mais que dobraram no período, passando de 15\% 
para $35,80 \%$ e das particulares pagas, que aumentaram de $6,9 \%$ para $9 \%$.

\section{Tabela 3 - Matriculas totais por dependência \\ administrativa- Chile - anos escolhidos}

\begin{tabular}{|c|c|c|c|c|}
\hline & \multicolumn{2}{|c|}{1981} & \multicolumn{2}{c|}{$\mathbf{2 0 0 0}$} \\
\hline & $\mathrm{N}$ & $\%$ & $\mathrm{~N}$ & $\%$ \\
\hline Fiscal & 2.215 .973 & 77,98 & & \\
\hline Municipal & & & 1.884 .320 & 53,71 \\
\hline Part.Subv. & 430.232 & 15,14 & 1.256 .116 & 35,80 \\
\hline Part.Pag. & 195.521 & 6,88 & 312.808 & 8,92 \\
\hline Corporações & & & 55.265 & 1,58 \\
\hline T0TAL & $\mathbf{2 . 8 4 1 . 7 2 6}$ & $\mathbf{1 0 0}$ & $\mathbf{3 . 5 0 8 . 5 0 9}$ & $\mathbf{1 0 0}$ \\
\hline Fonte: MIINEDUC.Compendio de Información Estadística
\end{tabular}

Educacional Año 2000

Se 0 atendimento educacional está sob responsabilidade das municipalidades e das particulares subvencionadas, o financiamento e o controle das políticas é praticamente todo centralizado no governo nacional, através das ações do MINEDUC.

A tabela 4 apresenta a participação do MINEDUC, das municipalidades e do Fundo Nacional de Desenvolvimento Regional (FNDR) do Ministério do Interior nos gastos públicos totais do país. Os gastos das municipalidades somados aos investimentos do FNDR têm uma participação muito pequena no financiamento público da educação chilena: juntos somavam 6,95\% do gasto público em 2000. Importante observar, no entanto, que a participação das municipalidades no financiamento da educação é uma novidade do sistema descentralizado posto em prática pelos militares, pois em 1980, as municipalidades não custeavam a educação. Na outra ponta - MINEDUC é responsável por mais de $90 \%$ do financiamento educacional público, sendo que em 2000, $74 \%$ dos recursos do Ministério eram utilizados para o pagamento das subvenções às municipalidades e às escolas particulares.
Tabela 4 - Gasto público por nível de governo - Chile -

\begin{tabular}{|c|c|}
\hline 1980 & 2000 \\
\hline
\end{tabular}

\begin{tabular}{|c|c|c|c|c|}
\hline & $N$ & $\%$ & $N$ & $\%$ \\
\hline MINEDUC( & $410.358,8$ & 93,33 & $1.289 .720,0$ & 33,55 \\
\hline
\end{tabular}

\begin{tabular}{|c|c|c|c|c|}
\hline Municipalidades & 0 & 0,00 & $62.319,6$ & 4,52 \\
\hline
\end{tabular}

\begin{tabular}{ccc|c|c|c|}
\hline Inversión(2) & $29.328,5$ & 6,67 & $26.575,6$ & 1,93 \\
\hline
\end{tabular}

\begin{tabular}{c|c|c|c|c|} 
TOTAL & $439.687,3$ & 100 & $1.378 .615,2$ & 100 \\
\hline Onte: MIINEDUC. Compendio de Informacion Estadistica
\end{tabular}

Fonte: MIIIVEDUC. Compenalo de Informacion Estadistic excetuados aqueles readizados na Educacão Superior. (2) Investimentos realizados pelo Ministério do Interior através do Fundo Nacional de Desenvolvimento Regional.

Em boa medida, a estrutura de financiamento decorre da organização unitária do Estado chileno, com suas decorrências na estrutura de arrecadaçãoedistribuiçãofiscal.Utilizandodados de 1991, Bagioli G. (1993) mostra a participação das municipalidades na receita fiscal nacional. Segundo o autor, do total de receitas chilenas, as municipalidades arrecadam diretamente $8,52 \%$, ficando o restante para a arrecadação do Governo Central. No entanto, quando se trata dos recursos disponibilizados para utilização direta pelos municípios este percentual mais que duplica. Enquanto o Governo Central fica com $78,65 \%$ dos recursos fiscais, as municipalidades ficam com $21,35 \%$.

As receitas diretas mais importantes dos municípios são o Imposto por Permissão de Circulação, cobrado dos veículos que circulam pelas vias públicas, a Contribuição de Licenças Municipais, cobrada a todos os estabelecimentos comerciais e de serviços, as Licenças para a fabricaçãoe comercialização de bebidas alcoólicas e o Imposto Territorial, cobrado aos proprietários de imóveis. As municipalidades são beneficiadas também com Recursos Externos Provenientes do Setor Público, para que realizem a prestação de serviços transferidos do Governo Central para as Comunas, como é o caso da educação.

A diferenciação da subvenção permite que o MINEDUC atue "discriminando positivamente" através de pagamentos adicionais, as regiões maisisoladas e a escolas rurais e que pertençam a regiões com um desenvolvimento econômico menor. O resultado dessa diferenciação pode ser visto nos gastos por aluno por região, tomando como referência apenas a componente subvenção realizada, pois as estatísticas educacionais não apresentam os gastos públicos por região do país. A tabela 5 mostra a diferença da subvenção média paga por aluno da Educação Geral Básica de cada uma das treze regiões. Tabela 5 - Subvenção média por aluno da educação geral
básica por regiẫo - Chile - 2000

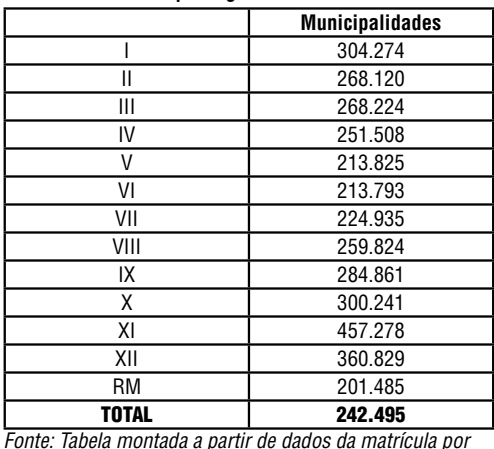

região e por dependência e da subvenção realizada para as municipalidades no ano de 2000. MINEDUC. Compendio de Información Estadistica Educacional.

(1) valores em milhôes de pesos.

(2) para o cálculo da média, os valores de subvenção transferidos foram convertidos para bilhões (mil millones)

É possivel identificar que a Região Metropolitana de Santiago (RM) é a região que recebe o menor valor por aluno, enquanto Região Xl é a que recebe a maior subvenção, quase duas vezes a subvenção média de todo a país neste nivel de ensino: 238.020 pesos. Em quatro regiões (V, VI, VII e RM) a subvenção média fica abaixo da média nacional. Essas regiões estão entre as sete com maior número de matrículas deste nível de ensino, inclusive a RM, que possui um terço das matrículas da Educação Básica chilena. Já as Regiões XI e XII, que apresentam as maiores taxas de repetência entre as regiões do país, são beneficiadas pelos maiores valores de subvenção transferidos pelo MINEDUC. Entretanto, há que estudar legislação para identificar se tal diferenciação é coerente com a realidade educaciona ou decorrente do baixo desenvolvimento econômico das mesmas.

Fica evidente, assim, que a estabilidade conferida às mudanças educacionais realizada no Chile durante a ditadura, levou a um sistema crescentemente apoiado na subvenção matrícula. As decorrências da continuidade política e do crescente subvencionamento matrícula foram a municipalização da oferta educacional e o crescimento vertiginoso da importância das escolas privadas na oferta de educação aos chilenos.

A realidade educacional chilena é, portanto, muito controvertida. Possui um sistema de atendimento educacional fortemente descentralizado ou privatizado convivendo com mecanismos de financiamento público predominantemente dirigidos pelo governo nacional. Foi protagonista de um ambicioso conjunto de transformações de inspiração liberal na gestão educacional. No entanto, a partir das ações do MINEDUC, além de ampliar os gastos educacionais durante os governos democráticos, realiza um intrincado mecanismo de transferência de recursos que beneficia sobremaneira as regiões mais pobres em detrimento das mais ricas e populosas, ao mesmo tempo em que facilitou a participação das famílias no financiamento da educação das escolas particulares subvencionadas, através do financiamento compartilhado. Componentes de um enigma que desperta admiração de alguns e critica de outros tantos, mas que precisa ser desvendado.

\section{Brasil: descentralização \\ desigualdades crônicas}

Enquanto o Chile definiu-se Unitário quando de sua independência, o Brasil, quando da Proclamação da República, em 1889, declarouse um Estado Federal. Oliveira (1995, p. 77 ) 
sentencia que "a adoção da forma federativa foi apenas uma solução de jure para acolher um status quo constituído pelas oligarquias regionais e provinciais já poderosas no Império". Um arranjo não incomum na experiência política brasileira: em 1831, a reforma constitucional, instituiu a monarquia federal e constitucional, com assembléias provinciais, executivos municipais e "divisão das receitas entre o governo central e as províncias" (CARVALHO, 1993, p. 60).

Oliveira (1995, p. 78-79) relativiza a historiografia brasileira que trata o período imperial como centralizado, justificando, no que tem a concordância de Carvalho (1993) com "a incapacidade de o Estado Imperial abranger a imensidão do território e a diversidade de sua formação". De um lado, a Monarquia revela a centralização política e administrativa expressa dentre outras coisas, pela prerrogativa do governo central nomear os presidentes das províncias. De outro, o controle territoria era assegurado às oligarquias regionais provinciais, responsáveis, dentre tantas coisas por "coletorias da fazenda, a guarda nacional e os bancos reais com poder de emissão".

Mesmo que este trabalho não tenha a pretensão de aprofundar esta reflexão, entende que "a Constituição de 88 definiu um novo arranjo federativo, com significativa transferência de capacidade decisória, funções e recursos do governo nacional para os estados e especialmente, para os municípios" (ALMEIDA 1995, p. 92), conferindo a estes o status de ente federado. Isso levou à afirmação de que se trata de um "sistema de três níveis (triplo federalismo)": "os três níveis de governo têm seus próprios poderes legislativos e os níveis federal e estaduais têm seus próprios poderes judiciários" (KUGELMAS \& SOLA, 1999, p. 69 SOUZA, 2005, p. 110)

Abstraindo que tal característica é estranha ao federalismo, tal qual seus fundadores estadunidenses conceberam, as mudanças constitucionais que fizeram os municípios brasileiros ganharem tanta importância é resultante do processo de redemocratização que, dentre outras coisas, buscava romper com as marcas de centralização do último período militar, mas também um novo capítulo dos arranjos do regime federativo brasileiro com forte influência dos grupos locais na distribuição de poder (KUGELMAS \& SOLA, 1999, p. 74)

A Educação Básica, inclusive o ensino obrigatório, está sob a responsabilidade dos poderes locais e de particulares desde período colonial e o advento da República e do regime federativo consolidou a descentralização educacional e manteve a União de fora das responsabilidades com o ensino primário. Com a autonomia dos estados, após a Constituição de 1891, foram deixadas à alçada destes as definições jurídicas sobre obrigatoriedade e gratuidade do ensino primário (CURY, 1996 2000). Muitos estados, num esforço de recuperar o déficit educacional, instituíram a gratuidade, mas transferiram responsabilidades de oferta de educação elementar para os municípios, a maioria deles mais pobres ainda (CURY, 2000).

Os anos 80 se caracterizaram por um intenso debate, voltado para a democratização do Estado brasileiro. A ditadura militar, instalada em 1964, efetivara uma política de significativa centralização das decisões, do comando político e dos recursos públicos ao nível do executivo federal. $O$ debate sobre a descentralização educacional teve, portanto, uma conotação muito diferente, pois a educação básica desde sempre fora descentralizada, ainda que numa mistura de responsabilidades dos estados e dos municípios

\section{O Sistema de ensino e}

\section{financiamento educaciona}

A LDB institui como primeiro nível de escolaridade aeducação básica, estabelecendo suas etapas, e reafirma a gratuidade do ensino público em todo e qualquer estabelecimento oficial, inclusive nas universidades públicas.

A educação infantil, de responsabilidade prioritária dos municípios, é oferecida às crianças entre zero e cinco anos de idade e deve ser ministrada em creches, para crianças entre zero e três anos de idade e pré-escolas, para crianças entre quatro e cinco anos de idade. O ensino fundamental, obrigatório e gratuito desde maio de 2005 teve sua duração mínima ampliada para nove anos, é responsabilidade prioritária de estados, Distrito Federal e municípios e deve iniciar aos seis anos de dade. O ensino médio, com duração mínima de três anos, é prioridade dos estados. Segundo a LDB o ensino médio deve oferecer aos alunos uma formação geral e, através da extensão de sua duração, pode oferecer formação técnica integrada à formação geral.

A Constituição Federal de 1988, em seu artigo 212 , fixou em $18 \%$ o comprometimento das receitas da União para a manutenção e o desenvolvimento do ensino (MDE) e manteve em $25 \%$ a vinculação mínima das receitas de impostos dos estados, municípios e do Distrito Federal, compreendida a proveniente de transferências constitucionais.

Desde 10 de janeiro de 2007, educação básica tem como fonte adicional de financiamento a contribuição social do salário-educação recolhida pelas empresas. Essa receita destinava-se anteriormente ao financiamento apenas do ensino fundamental.

A União, além de organizar e financiar o sistema federal de ensino e dos territórios deve prestar assistência técnica e financeira aos estados, ao Distrito Federal e aos municípios para 0 desenvolvimento de seus respectivos sistemas de ensino e o atendimento prioritário escolarização obrigatória. As funções supletivas e redistributivas da União se efetivam através de uma série de programas destinados, em especial, à garantia do ensino fundamental, aos quais somam-se outros que beneficiam os demais níveis de ensino. Dentre os programas do Ministério da Educação encontram-se o Programa Nacional do Livro Didático, programa de apoio ao transporte do escolar, programa de transferência de recursos para as escolas e tantos outros.

A função redistributiva foi inaugurada, durante $\circ$ governo de Fernando Henrique
Cardoso, que instituiu, através da Emenda Constitucional 14, o FUNDEF, Fundo que vigorou até dezembro de 2006 e financiava o ensino fundamental. O Fundo redistribuía $60 \%$ de algumas das receitas educacionais dos estados e seus municípios em função do número de matrículas no ensino fundamenta regular. A União complementava apenas os Fundos estaduais que não dispusessem da quantidade mínima de recursos por aluno, fixada por decreto presidencial, o que poucas vezes alcançou a cifra anual de $\mathrm{R} \$ 400$ milhões.

O FUNDEF foi substituído pelo FUNDEB, criado pela EC 53/2006. O novo Fundo ira redistribuir, a partir de $2009,80 \%$ das principais receitas educacionais dos estados e municípios em função de todas as matrículas públicas da educação básica. A União, a partir de 2010 deverá complementar este Fundo com pelo menos $10 \%$ do volume de recursos movimentado nacionalmente, o que deve representar um volume de recursos próximo de $\mathrm{R} \$ 5$ bilhões.

\section{A descentralização e o} financiamento educacional pelos diferentes níveis de governo

As matrículas da educação básica se distribuem entre as diferentes dependências administrativas em movimentos coerentes com a divisão de responsabilidades estabelecida na Constituição Federal e na Lei de Diretrizes e Bases da Educação Nacional, o que será tratado a seguir. No entanto, evidenciam-se dois aspectos que também são essenciais: primeiro é o impressionante crescimento da matrícula nos diferentes níveis de ensino da educação básica. As matrículas de pré-escola cresceram, entre 1980 e 2000 , mais de $230 \%$, as matrículas de ensino médio aumentaram $190 \%$ e, mesmo as matrículas de ensino fundamenta obrigatório, cresceram $58 \%$, agregando mais de 13 milhões de novos alunos em 20 anos.

O segundo aspecto é aquele já assinalado, mas que fica mais evidente com dados quantitativos: a ausência da União na garantia 
da educação básica e a correspondente responsabilidade de estados e municípios.

A tabela 6 mostra a responsabilidade dos diferentes níveis de governo com a garantia da educação básica. Quandose trata da pré-escola, em 2000, os municípios tinham quase $68 \%$ das matrículas, coerentes com a responsabilidade pela garantia desse nível de ensino. Os estados possuíam mais de 7,5\% e a União pouco mais de 1.200 matrículas. Um dado importante deste nível de ensino é que, apesar do crescimento das matrículas privadas, proporcionalmente elas caíram pela metade quando se toma o ano de 1980 como base de comparação.

\section{Tabela 6 - Matrículas por dependência administrativa e} por nivel de ensino - Brasil - 2000

\begin{tabular}{|c|c|c|c|c|c|c|}
\hline & Prí-essola & 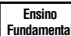 & $\begin{array}{l}\text { Ensinio } \\
\text { Mindio }\end{array}$ & & & \\
\hline & $\bar{N}$ & $\%$ & $N$ & $\%$ & $\mathrm{~N}_{\mathrm{N}}$ & \begin{tabular}{|l|}
$\%$ \\
\end{tabular} \\
\hline & \begin{tabular}{|l|l|}
1.247 \\
\end{tabular} & 0.03 & \begin{tabular}{|l|l}
27.810 \\
\end{tabular} & 0,08 & 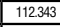 & \begin{tabular}{|l|l|l}
1.37 \\
\end{tabular} \\
\hline adual & 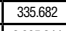 & 7,59 & 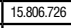 & 44,25 & 6.662 .727 & \begin{tabular}{|l|l|}
81,32 \\
\end{tabular} \\
\hline icipal & \begin{tabular}{|l|}
2.9952 .44 \\
\end{tabular} & 67,75 & $\mid 16.694 .171$ & 46,74 & \begin{tabular}{|l}
266.459 \\
\end{tabular} & \begin{tabular}{|l}
3,23 \\
\end{tabular} \\
\hline & \begin{tabular}{|l|l}
1.089 .159 \\
\end{tabular} & $\begin{array}{l}24,63 \\
\end{array}$ & \begin{tabular}{|l|l} 
\\
\end{tabular} & 8,93 & 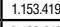 & \begin{tabular}{|l|l|}
14,08 \\
\end{tabular} \\
\hline Tote & | 4.421.332 & 100 & | 35.7717.948 & 100 & \begin{tabular}{|l|}
8.192 .948 \\
\end{tabular} & 100 \\
\hline
\end{tabular}

No ensino médio, são os estados que assumiram a expansão, chegando a 2000 com mais de $80 \%$ das matrículas. Os municípios tinham pouco mais de $3 \%$ e a União, $137 \%$, menos da metade dos $3 \%$ que tinha em 1980 Dado significativo também é a proporção do atendimento privado, que até 1980 , era superio a 46\%, igualando-se ao dos estados e, em 2000 tinha despencado para $14 \%$.

As matrículas de ensino fundamental revelam movimentos um bocado mais intrincados. Em 2000, os municípios já possuíam mais matrículas que os estados e, atualmente, possuem mais matrículas que todas as demais dependências administrativas somadas. No entanto, este salto nas matrículas municipais se deu a partir dos anos 1996, com a vigência do FUNDEF. Até então as matrículas municipais oscilavam na faixa de 30 a $33 \%$. Importante destacar que os municípios ocuparam a posição que os estados detinham em 1980 e, ao assumirem a maior parte da expansão ocorrida, empurram progressivamente as matrículas estaduais para a posição que era das municipais em 1980.
A responsabilidade pelo atendimento educacional, associada à estrutura federa do Estado brasileiro, coloca os estados municípios no importante papel de assegura a maior parte do financiamento da educação básica. A tabela 7, abaixo, mostra que, somados, estados e municípios contribuem com mais de $83 \%$ dos gastos públicos educacionais, sendo que os municípios rivalizam com os estados, com gastos que chegam a quase $39 \%$. Se considerarmos que, nos gastos da União, estão ncluídas as despesas com ensino superior onde se concentram os gastos deste nível de governo, a participação dos municípios e dos estados no financiamento da educação básica é ainda maior. Outro dado importante mostra que tanto a União como os estados, que também têm importantes despesas com ensino superior, diminuíram a presença no financiamento educacional quando se compara 1980 com 2000.

\section{bela 7 - Gastos em educação no Brasil por nível de}

\begin{tabular}{|c|c|c|}
\hline \multirow{2}{*}{ Níveis } & \multicolumn{2}{|c|}{ Gastos em educaçã } \\
\cline { 2 - 3 } & $\boldsymbol{t}$ & $\%$ \\
\hline União & $12.787 .873 .400,00$ & 16,67 \\
\hline Estados & $34.144 .040 .300,00$ & 44,50 \\
\hline Municííis & $29.800 .491 .900,00$ & 38,84 \\
\hline Total Gastos & $\mathbf{7 6 . 7 3 2 . 4 0 5 . 6 0 0 , 0 0}$ & $\mathbf{1 0 0}$ \\
\hline Fonte: 1999 - IPEADISOOC, IBGE/MP \& INEP/MEC.
\end{tabular}

Os ves constantes pelo IGP-DI-FGV

sunicipios, em 1990, foram estimados a partir dos valores de gastos das capitis

Os três níveis de governo possuem fontes diversificadas de receitas, além de estados municípios serem beneficiários de transferências intergovernamentais. As principais receitas da União são o Imposto de Renda - IR e Imposto sobre Produtos Industrializados - IPI. Os estados têm no Imposto sobre Circulação de Mercadorias e Serviços - ICMS, a principa fonte de receita, ao qual se somam o Imposto sobre Propriedade de Veículos Automotores - IPVA e as transferências da União relativas ao Fundo de Participação do Estados - FPE e à Lei Complementar 87/96 e IPI-exportação. Os municípios têm uma forte dependência das transferências de ICMS e de IPVA dos estados, além das transferências do Fundo de Participação dos Municípios - FPM, feitas pela União. As principais receitas municipais são Imposto Predial e Territorial Urbano - IPTU e o Imposto sobre Serviços - ISS, entretanto, de modo geral, apenas as capitais e os municípios mais desenvolvidos têm uma captação significativa de recursos destas fontes. grande maioria dos municípios brasileiros é dependente das transferências de FPM e de ICMS. O Estudo Tributário ${ }^{\circ} 13$, da Receita Federal, mostra que, em 2003, a União era beneficiária de $57,49 \%$ dos recursos tributários nacionais, os estados $25,21 \%$ e os municípios $17,29 \%$

O fato dos municípios brasileiros terem alcançado tal proporção de crescimento de suas despesas educacionais não é suficiente para eliminar as desigualdades existentes entre diferentes municípios, diferentes estados e diferentes regiões. A tabela 8 mostra o gasto por aluno por nível de ensino e por região do país, permitindo a comparação com o gasto médio do país.

Tabela 8: Gasto público por aluno por nível de ensino Brasil e Regiōes - 1995 e 1999

\begin{tabular}{|c|c|c|c|c|c|c|}
\hline & \multicolumn{3}{|c|}{1995} & \multicolumn{3}{|c|}{1999} \\
\hline & Ed. & Ens. Fund & $\begin{array}{l}\text { Ens. } \\
\end{array}$ & $\begin{array}{l}\text { Ed. } \\
\text { Ed }\end{array}$ & Ens. & \begin{tabular}{|l} 
Ens. \\
Médi
\end{tabular} \\
\hline Brasil & 1689 & 1371 & 1495 & $\begin{array}{l}1709 \\
\end{array}$ & 1278 & \begin{tabular}{|l|l|}
1190 \\
\end{tabular} \\
\hline \begin{tabular}{|l|l|} 
Regïaño \\
\end{tabular} & 842 & 923 & 1040 & 1168 & 1053 & 1004 \\
\hline \begin{tabular}{|l|} 
Regiä́o \\
\end{tabular} & 805 & 883 & 1086 & 1037 & 9937 & \begin{tabular}{|l|l|}
979 \\
\end{tabular} \\
\hline \begin{tabular}{|l|} 
Regiāo \\
\end{tabular} & 3034 & 1727 & 1731 & 2348 & 1529 & 1256 \\
\hline Regiäo & 2010 & 1582 & 1326 & 1758 & 1484 & \begin{tabular}{|l|l} 
\\
\end{tabular} \\
\hline 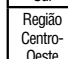 & 1356 & 1473 & 1644 & 1669 & 1552 & \begin{tabular}{|l|l|}
1500 \\
\end{tabular} \\
\hline
\end{tabular}

1) Gastos por nivel de ensino incluem todas as suas modalidades

(2) Valores constantes pelo IGP-DI-FGV

O gasto público médio por aluno do ensino obrigatório era, em 1999, de $\mathrm{R} \$ 1.278,00$. Entretanto, na Região Nordeste, esse índice era $26,7 \%$ menor e, na Região Norte, era quase $18 \%$ menor. Em contraste, nas Regiões Centro-Oeste Sudeste, o gasto por aluno do ensino fundamental era, respectivamente, $21,4 \%$ e $19,5 \%$ superior à média nacional. É verdade, no entanto, que entre 1995, ano em que não havia ainda o mecanismo redistributivo instituído com o FUNDEF, e 1999, a desigualdade na capacidade de financiamento das matrículas foi reduzida. Em 1995, o gasto por aluno da Região Sudeste era 95\% maior que da Região Nordeste. Em 1999, o gasto da Região com a maior média-a Centro-Oeste - em relação Região com a menor - a mesma Região Nordeste - havia caído para $65,6 \%$. Há que se observar que parte desta redução se deu mais pela redução da capacidade de gastos por aluno das regiões mais ricas do que pelo aumento da capacidade de gastos das regiões mais pobres.

Esse quadro confirma não apenas as condições de desigualdade, mas também a dificuldade de promover a redução dessas desigualdades com as medidas possíveis a partir da ação de financiamento da União.

\section{Um primeiro balanço}

A análise da realidade do Brasil do Chile mostra que a descentralização das responsabilidades pelo atendimento educacional, o papel e a capacidade de financiamento educacional do governo central são determinantes na possibilidade de redução das desigualdades educacionais.

O Brasil, que possui um sistema educacional totalmente descentralizado convive, por força da estrutura federativa, com um sistema tributário que assegura aos governos subnacionais uma participação maior na receita fiscal. Também fixa responsabilidades maiores para os estados e municípios no financiamento educacional. Com isso, estados e municípios, que têm mais de $83 \%$ de responsabilidade no financiamento daEducaçãoBásica, dependem predominantemente de seus recursos para atuar na redução das desigualdades.

Mesmo mecanismos redistributivos afiançados pela União, como foi o FUNDEF e como é o FUNDEB, são pouco eficazes na redução das desigualdades expressas na 
capacidade de financiamento das matrículas entre as diferentes regiões.

No Chile, onde a descentralização da oferta de educação convive com um sistema de financiamento predominantemente dependente do governo nacional, são maiores e mais evidentes as possibilidades de redução das desigualdades do financiamento educacional entre as diferentes regiões. Contribui para isso, o fato do governo nacional concentrar boa parte da receita fiscal, permitindo-lhe fazer uma interessante diferenciação da subvenção das matrículas, em benefício das regiões economicamente mais pobres.

Não podemos ignorar, no entanto, que parte das políticas dos governos chilenos do período democrático pós-1990 são determinadas pelo esforço de legitimação e superação das marcas deixadas pela ditadura militar na vida dos chilenos. Marcas que carregam consigo as receitas do liberalismo com as quais os governos dos socialistas e da democracia-cristã têm tido dificuldades de romper e, ao contrário, em alguns casos, têm dado seqüência, aperfeiçoando-as.

Independentemente dos elementos considerados acima, fica evidente que as pressões sociais sobre governos unitários asseguram melhores condições para a redução das desigualdades educacionais.

Bibliografia

ABRUCIO, F. L. Reforma política e federalismo. Desafios para a democratização brasileira. In: VANNUCHI, P.; BENEVIDES, M. V.; KERCHE, F. (orgs). Reforma Política e Cidadania. São Paulo: Fundação Perseu Abramo, 2003. p. 225-265.

ALMEIDA, M. H. T. Federalismo e políticas sociais. Revista Brasileira de Ciências Sociais. São Paulo, v.10, n 28, jun de 1995, p. 88-108.

ARRETCHE, M. Relações Federativas nas Políticas Sociais. Educação e Sociedade, Campinas, UNICAMP-CEDES, v. 23, n. 80, p. 25-48, set. 2002.

BAGIOLI G. R. Estado y Proyecciones de las Rentas Municipales. In: Serie Estudios Municipales. Santiago (CL): Corporación de Promoción Universitária, Programa de Capcitación em Políticas Sociales 1993, p. 225-262

CARVALHO J.M. Federalismo y centralización en el Imperio brasileño: história y argumento. In CARMAGNANI, M. (org.). Federalismo latinoamericanos: México/Brasil/Argentina. México: Fundo de Cultura Econômica, 1993. p. 51-80.

COX, C. Las políticas educacionales de Chile en las últimas dos décadas del siglo XX. In: COX C. (org.). Políticas educacionales en el cambio del siglo: la reforma del sistema escolar de Chile. Santiago de Chile (CL), Editorial Universitaria, 2003, p. 19-113.

CURY, C. R. J. A educação e a primeira constituinte republicana. In: Fávero, O. (org.). A educação nas constituintes brasileiras (1823-1988). Campinas, Editora Autores Associados, 1996. A educação como desafio na ordem jurídica. In: LOPES, E. M. T.; FILHO, L. M. F.; VEIGA, C. G. (orgs.). 500 anos de educação no Brasil. Belo Horizonte: Autêntica, 2000. p. 567-584. ESPINOZA, O.; GONZÁLEZ, L. E. La experiencia del proceso de desconcentración y

descentralización educacional en Chile - 1974-1989. Santiago(CL), CIDE, 1993.

KUGELMAS, E.; SOLA, L. Recentralização/Descentralização: dinâmica do regime federativo no Brasil dos anos 90. Tempo Social, São Paulo, USP, v. 11, n. 2, p. 63-81, out. 1999

LEAL, A. I.; CASTRO, G. W. El proyecto educacional autoritário del régimen militar chileno. ProPosições, Campinas, UNICAMP-FE, n. 6, p. 87-104, dez. 1991.

MORAES, R. C. C. Neoliberalismo: de onde vem, para onde vai? São Paulo: SENAC Editora, 2001

OLIVEIRA, F. A crise da Federação: da oligarquia à globalização. In: AFFONSO, Rui de Brito Álvares;
SILVA, Pedro Luiz Barros (orgs.). A Federação em perspectiva: ensaios selecionados. São Paulo: FUNDAP, 1995. p. 77-90.

RAMA, G. W. Estrutura e movimentos sociais no desenvolvimento da educação popular. In RAMA, G. W. (org.). Mudanças educacionais na América Latina: situações e condições. Fortaleza, Universidade Federal do Ceará, 1983. p. 13-84.

SOUZA, C. Governos e sociedades locais em contextos de desigualdades e de descentralização. Ciências \& Saúde Coletiva. São Paulo, 7 (3): 431-442, 2002

I CONGRESSO NACIONAL E I ENCONTRO LATINO-AMERICANO DE ESTUDOS COMPARADOS EN EDUCACIÓN. 2007, Buenos Aires. Anais. Buenos Aires: AEC, 2007. 